\title{
Manganese absorption by water hyacinth and its study as a raw material in nanotechnology
}

\author{
M. C. Jiménez-Moleón ${ }^{1}$, M. T. Mota-González ${ }^{1}$ \\ \& J. A. Ascencio-Gutiérrez ${ }^{2}$ \\ ${ }^{I}$ CIRA, Universidad Autónoma del Estado de México, México \\ ${ }^{2} I C F$, Universidad Nacional Autónoma de México, México
}

\begin{abstract}
Metal presence is a serious pollution problem in natural or treated water. The water hyacinth (Eichhornia crassipes) is an aquatic plant known for its high capacity to absorb metals. However, to use water hyacinths in a sustainable pollution removal process, the parameters that affect the process of metal absorption and the disposal of the contaminated organic matter must be studied; these being the aims of this work.

Water hyacinth assays were carried out in distilled water and the influence of $\mathrm{Mn}^{2+}$ initial concentrations $\left(\mathrm{C}_{\mathrm{o}}: 10,50,100 \mathrm{mg} / \mathrm{L}\right)$ and initial $\mathrm{pH}\left(\mathrm{pH}_{0}: 3,5,7\right)$ were analyzed. Parameters such as $\mathrm{pH}$, electric conductivity (EC), and residual $\mathrm{Mn}^{2+}$ were also measured. At the end of every assay, $\mathrm{Mn}$ was quantified in the different sections of the water hyacinth (root "R", petiole "P" and leaf "L") by atomic absorption spectrometry, and the presence of metal aggregates was detected by TEM microscopy.

E. crassipes did not neutralize its growing medium. The EC was not a good control parameter for absorption, increased with time. The water hyacinth was capable of efficiently removing $\mathrm{Mn}^{2+}$ from the solutions. It can be seen two phases of absorption (a rapid one followed by a slow absorption phase nearly linear). With increasing $\mathrm{C}_{\mathrm{o}}$, the absorbed $\mathrm{Mn}^{2+}$ increased, but the percentage of absorption during the rapid phase diminished. The final percentage of absorption increased with $\mathrm{pH}_{0}$ independently of $\mathrm{C}_{0}$. The water hyacinth is capable of effectively translocating $\mathrm{Mn}$. The bioconcentration factor (BCF) diminished with $\mathrm{C}_{\mathrm{o}}$, and increased with $\mathrm{pH}_{\mathrm{o}}$.
\end{abstract}


Finally, aggregates of $\mathrm{Mn}^{0}$ were detected in nanometric size (between 5 and $20 \mathrm{~nm})$ in all the sections, being suggested that E. crassipes can turn as raw material in nanotechnology.

Keywords: absorption, bioconcentration factor, E. crassipes, initial concentration, initial $\mathrm{pH}, \mathrm{Mn}$, nanotechnology, translocation, water hyacinth.

\section{Introduction}

Floating aquatic plants are an effective means of removing metals in water, as they have the ability to capture and accumulate them in their tissues. Although it has been declared as the worst aquatic weed worldwide [1], the macrophyte that seems to have the greatest potential for use in controlling polluted water, most cited and most dominant in tropical regions, is the water hyacinth, Eichhornia crassipes (Mart.) Solms. This has been the subject of several investigations to determine the adsorption capacity of organic and inorganic pollutants [2-4], although few cases have presented the influence of experimental conditions on the process. This article presents the effect on the absorption of $\mathrm{Mn}^{2+}$ that this macrophyte has at different initial metal concentrations and $\mathrm{pH}$ in neutral and acidic range, as the mobility of metal in solution is greatly reduced at basic $\mathrm{pH}$ values by the generation of hydroxides.

Despite the growing interest in soft technologies, because of its low operating and maintenance costs, they still represent an environmental problem, particularly when it comes to the removal of heavy metals in solution is the disposing should be given to the plant once it has succeeded in removing contaminant from the medium, at the expense of being transformed into a residual contaminated organic material. The present proposal is to examine the deposited metal within the water hyacinth, with the aim of analyzing whether they correspond to aggregates of nanometric size that can be used in one of the many nanotechnology fields, helping to consolidate the newly opened bridge between biotechnology and science of materials [5, 6], achieving a very favorable alternative solution to the problem of disposal of the water hyacinth biomass in which metal contaminants are concentrated.

\section{Methodology}

To realize the contact experiments, healthy plants with similar characteristics (size, wet weight, number of leaves, size and volume of roots) were collected in a water body of the valley of Toluca, State of Mexico, Mexico: Bordo de San Martín La Puerta.

In order to remove as much material and substances attached to the roots of the plants as possible 3 pretreatments were tested:

a) Rinse the plants with tap water, carefully trying to remove as much material attached to the root of the plants;

b) Wash roots gently with a sponge; and

c) Acid bath (pH 5). 
After any of the above procedures, the water hyacinth was put in contact with a nutrient solution $\left(900 \mathrm{~mL}: 0.85 \mathrm{~g} / \mathrm{L} \mathrm{Ca}\left(\mathrm{NO}_{3}\right)_{2} \cdot 4 \mathrm{H}_{2} \mathrm{O}, 2.00 \mathrm{~g} / \mathrm{L} \mathrm{KH}_{2} \mathrm{PO}_{4}\right.$ and $3.69 \mathrm{~g} / \mathrm{L} \mathrm{MgSO}_{4} \cdot 7 \mathrm{H}_{2} \mathrm{O}$ [7]) for 3 days. This nutrient solution was changed every 24 hours. Finally, to assess the most suitable pretreatment, three individual plants from each of the procedures specified above were exposed to a solution containing $10 \mathrm{mg} \mathrm{Mn}^{2+} / \mathrm{L}$ and it was elected the pretreatment that allowed the least amount of residual metal after 10 days: pretreatment a). Thus, plants were washed thoroughly with tap water and kept in a nutrient-rich solution for 3 days, changing it every 24 hours.

Bioassays were conducted individually (three repetitions), at room temperature in 1L-vessels with $900 \mathrm{~mL}$ of distilled water. The initial concentrations of $\mathrm{Mn}^{2+}$ studied were 10, 50 and $100 \mathrm{mg} / \mathrm{L}$ and, with each concentration, the initial $\mathrm{pH}$ was adjusted to 3,5 and 7 , with ultrapure $\mathrm{NaOH}$ or $\mathrm{HCl}$. The monitoring parameters were residual $\mathrm{Mn}^{2+}$ in water, $\mathrm{pH}$ and Electric Conductivity (EC), these two measures were polarographic while the $\mathrm{Mn}^{2+}$ concentrations were analyzed by atomic absorption, with equipment Varian, model Spectra 600, conditioned by graphite furnace or flame, depending on the concentration range to determine. Water samples were filtered with Whatman No. 41 filter paper (pore size $20-25 \mu \mathrm{m}$ ) and 1 drop of ultrapure acid $_{3}$ was added for preservation, which took place at $4^{\circ} \mathrm{C}$ until analysis.

At the end of each assay, the water hyacinths were sectioned in roots (R), petioles (P) and leaves (L), processing the main part of each segment to determine the amount of metal absorbed, while a small part was prepared for analyzing the possible presence of metallic aggregates generated inside the plant. Since the variation obtained in the residual $\mathrm{Mn}^{2+}$ in the different replicates was very consistent between them and, as discussed above, the plants were selected with similar characteristics, for determining the concentration of Mn within the sections of the plants, all the different parts of the water hyacinth corresponding to the repetitions of a determined assay were put together. Each section was dried in a porcelain dish in an oven at $100^{\circ} \mathrm{C}$ until constant weight, approximately $15 \mathrm{~h}$, then the biomass was milled and the samples digested. It is important to note that several digestion techniques were used [8-11] including two techniques described in the Mars 5 microwave manual, it was necessary to make a change to one of these last techniques (table 1), to obtain transparent and colorless samples.

Table 1: $\quad$ Experimental conditions for microwave digestion of samples.

\begin{tabular}{|c|c|c|c|c|}
\hline Stage & $\begin{array}{c}\text { Power } \\
(\mathbf{\%})\end{array}$ & $\begin{array}{c}\text { Ramp } \\
(\mathbf{m i n})\end{array}$ & $\begin{array}{c}\text { Temperature } \\
\left({ }^{\mathbf{0}} \mathbf{C}\right)\end{array}$ & $\begin{array}{c}\text { Retention } \\
(\mathbf{m i n})\end{array}$ \\
\hline 1 & 100 & $10: 00$ & 200 & $5: 00$ \\
\hline \multicolumn{5}{|c|}{ To wait the temperature diminished to $50^{\circ} \mathrm{C}$. Approximated time: $30 \mathrm{~min}}$. \\
\hline 2 & 100 & $10: 00$ & 200 & $5: 00$ \\
\hline
\end{tabular}


Finally, the presence of clusters of $\mathrm{Mn}^{0}$ was studied through electron energy loss spectroscopy (EELS), optical microscopy and transmission electronic microscopy (TEM) using a Jeol JEM20 for TEM observations at low magnifications, and a Tecnai 200 TEM high-resolution images.

\section{Results and discussion}

With regard to the monitoring parameters behavior, during the different tests, regardless of the initial value, $\mathrm{pH}$ tended to stabilize slightly above 5 , perhaps related to the equilibrium of $\mathrm{CO}_{2}$ in water, so the water hyacinth did not neutralize its growth medium, against what has been reported in the literature [2, 12].

The minimum value of the EC responded to the initial measure and the maximum value was recorded in the last days of the testing, that is, the EC increased with time, demonstrating that it is not a good parameter for monitoring metal absorption in distilled water. In fact, the increase in EC was particularly strong towards the end of the trials, probably due to leaching of substantial quantities of inorganic and organic nutrients at the beginning of the decay phase $[11,13]$.

Fig. 1 shows the absorption of $\mathrm{Mn}^{2+}$ over time for the different initial conditions studied. In general, as it was reported in the literature for other metals [14-16], that when increasing $\mathrm{C}_{0}$, the absorption rate decreased, so the lower concentrations required less contact time to achieve the same absorption percentage, probably because of the saturation of the absorption sites in the roots at higher concentrations.

On the other hand, the amount of metal absorbed by the end of the bioassays was clearly influenced by the initial $\mathrm{pH}$ value, as shown in fig. 2 , increasing the $\mathrm{pH}_{0}$, the amount absorbed also increased with an almost linear dependence. The absorption was less at lower $\mathrm{pH}$ values, might be due to the root potential damage and to the reduction in the number of sites in anionic form.

In fig. 1, the existence of two absorption phases was also observed: an initial fast absorption phase followed by a slow almost linear one. The first absorption phase lasted 7 hours approximately, in which it was removed, on average, $51.1 \%, 29.4 \%$ and $18.8 \%$ for the initial concentrations of $10 \mathrm{mg} / \mathrm{L}, 50 \mathrm{mg} / \mathrm{L}$ and $100 \mathrm{mg} / \mathrm{L}$, respectively, showing that the percentage of metal absorbed during the fast phase decreased with increasing $\mathrm{C}_{0}$, the same trend as published in $\mathrm{Cd}$ absorption assays [14].

It is notable that, with the middle initial concentration, $50 \mathrm{mg} \mathrm{Mn}^{2+} / \mathrm{L}$, after the slow phase could be observed that the absorption rate was again increased, suggesting that the absorption process may have a cyclical behavior. Thus, as it is generally accepted, if the fast phase is where the metal absorption from the bulk takes place, while during the slow phase, what prevails (rather than the removal of metal from the liquid phase) is the release of absorption sites in roots due to the translocation of the metal to the aerial parts of the plant, it would be logical to think that once these new absorption sites appeared into the roots, the process rate would increase again, by a new phase of net absorption from the 


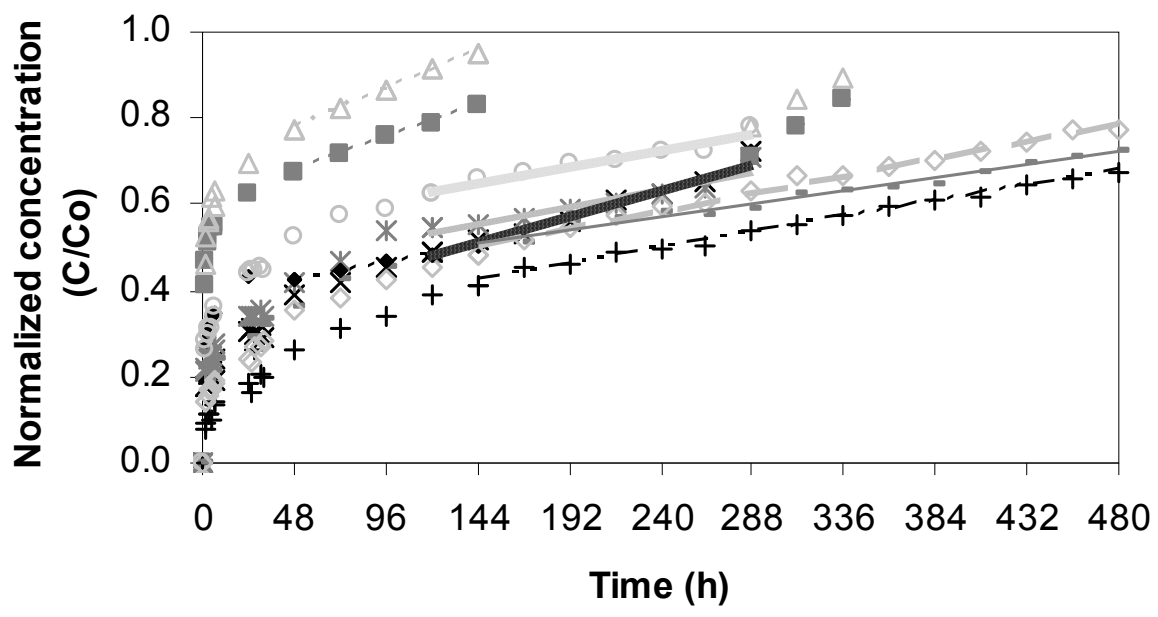

$\begin{array}{lll}\bullet 10 \mathrm{mg} / \mathrm{L}, \mathrm{pH} 3 & -10 \mathrm{mg} / \mathrm{L}, \mathrm{pH} 5 & \triangle 10 \mathrm{mg} / \mathrm{L}, \mathrm{pH} 7 \\ \times 50 \mathrm{mg} / \mathrm{L}, \mathrm{pH} 3 & * 50 \mathrm{mg} / \mathrm{L}, \mathrm{pH} 5 & \circ 50 \mathrm{mg} / \mathrm{L}, \mathrm{pH} 7 \\ +100 \mathrm{mg} / \mathrm{L}, \mathrm{pH} 3 & -100 \mathrm{mg} / \mathrm{L}, \mathrm{pH} 5 & \diamond 100 \mathrm{mg} / \mathrm{L}, \mathrm{pH} 7\end{array}$

Figure 1: Normalized concentration $(\mathrm{C} / \mathrm{Co})$ vs. time.

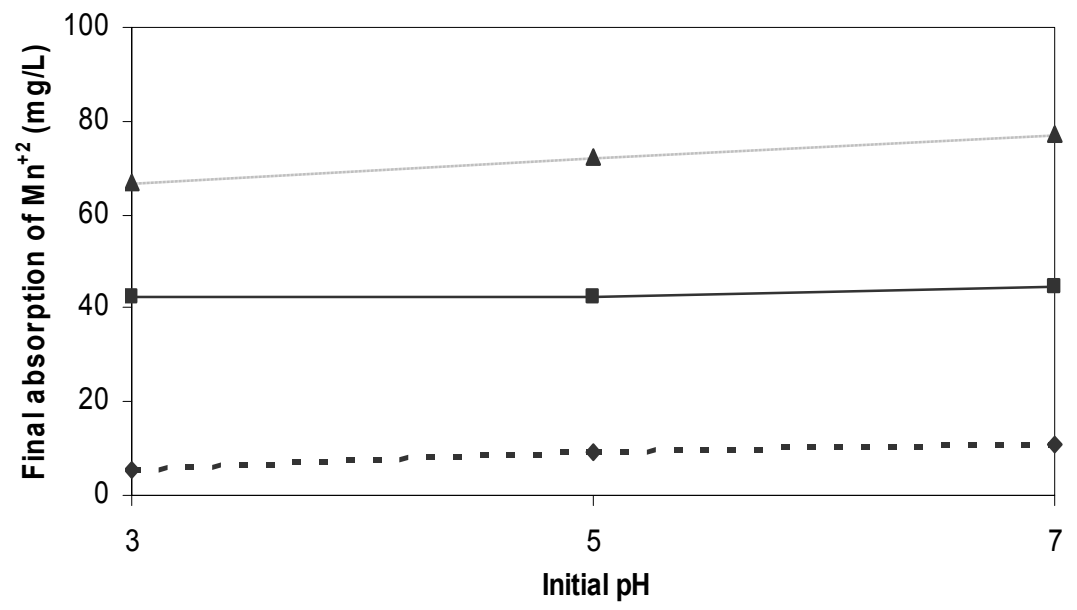

$\because---100 \mathrm{mg} / \mathrm{L} \longrightarrow-50 \mathrm{mg} / \mathrm{L} \longrightarrow 10 \mathrm{mg} / \mathrm{L}$

Figure 2: $\quad$ Final absorption of $\mathrm{Mn}^{2+}(\mathrm{mg} / \mathrm{L})$ depending on the initial $\mathrm{pH}$. 
liquid phase. This phenomenon was not appreciated in the other initial concentrations studied, may be due to the low residual concentration at the end of the slow phase when it was on $10 \mathrm{mg} / \mathrm{L}$ and to a contact time not sufficient in the case of higher concentration, $100 \mathrm{mg} / \mathrm{L}$.

The $\mathrm{Mn}$ concentrations in each section within E. crassippes are shown in table 2, along with the percentage that they represented, related with the water hyacinth translocation capacity under each experimental conditions studied.

In the data presented in table 2 , it was noteworthy that the concentration inside the plant was a function of the $\mathrm{C}_{0}$ as well as the $\mathrm{pH}_{0}$, increasing the metal concentration in the plant with any of these two parameters.

It is also shown in table 2 that the water hyacinth had a good capacity for $\mathrm{Mn}$ translocation. Even with the lowest concentration studied, independent of $\mathrm{pH}$, the root was the section that reached lower metal concentration, perhaps because the contact time was enough to achieve a good translocation of $\mathrm{Mn}$ within the plant. While at $50 \mathrm{mg} / \mathrm{L}$ and $100 \mathrm{mg} / \mathrm{L}$, the order of the Mn concentration was $\mathrm{R}>\mathrm{P}>$ $\mathrm{L}$, in similar percentages to those reported for other metals such as $\mathrm{Cd}, \mathrm{Pb}$, and Sr [10].

Table 2: Concentration of $\mathrm{Mn}$ within the water hyacinth, $\mathrm{mg} \mathrm{Mn} / \mathrm{kg}(\mathrm{dw})$ and $\%$.

\begin{tabular}{|c|c|c|c|c|c|c|c|}
\hline \multicolumn{2}{|c|}{ Initial conditions } & \multicolumn{2}{|c|}{$\mathbf{R}$} & \multicolumn{2}{|l|}{$\mathbf{P}$} & \multicolumn{2}{|c|}{$\mathbf{L}$} \\
\hline $\begin{array}{c}\mathrm{C}_{\mathrm{o}}, \\
\mathrm{mg} / \mathrm{L}\end{array}$ & $\mathrm{pH}_{\mathrm{o}}$ & $\begin{array}{c}\mathrm{mg} / \mathrm{kg} \\
\text { (dw) }\end{array}$ & $\%$ & $\mathrm{mg} / \mathrm{kg}(\mathrm{dw})$ & $\%$ & $\begin{array}{c}\mathrm{mg} / \mathrm{kg} \\
\text { (dw) }\end{array}$ & $\%$ \\
\hline \multirow{3}{*}{10} & 3 & 906 & 29 & 1224 & 40 & 960 & 31 \\
\hline & 5 & 1110 & 28 & 1244 & 32 & 1564 & 40 \\
\hline & 7 & 1451 & 27 & 2151 & 40 & 1784 & 33 \\
\hline \multirow{3}{*}{50} & 3 & 4235 & 48 & 3433 & 39 & 1219 & 14 \\
\hline & 5 & 4755 & 48 & 3565 & 36 & 1486 & 15 \\
\hline & 7 & 5966 & 52 & 3761 & 33 & 1704 & 15 \\
\hline \multirow{3}{*}{100} & 3 & 10016 & 53 & 6663 & 35 & 2216 & 12 \\
\hline & 5 & 10826 & 53 & 6942 & 34 & 2742 & 13 \\
\hline & 7 & 16488 & 65 & 6642 & 26 & 2084 & 8 \\
\hline
\end{tabular}

Subsequently, the bioconcentration factor (BCF) was determined according to the following equation:

$$
B C F=\frac{\text { metal concentration in plant }\left(\frac{\mathrm{mg}}{\mathrm{kg}}\right)}{\text { residual metal concentration in water }\left(\frac{\mathrm{mg}}{\mathrm{L}}\right)}
$$

Table 3 showed that the BAF decreased when increasing the metal initial concentration as well as generally accepted: by increasing the metal concentration in water, the amount absorbed (table 2) increased but the bioconcentration factor decreased $[2,15,17]$. In table 3 , the importance of the initial $\mathrm{pH}$ could also been seen, because the BCF was clearly superior at any of 
the initial concentrations under study, when that parameter was initially adjusted to the neutrality.

Thus, taking into account the concentration values within the plant (table 2) and the BCF data obtained (table 3), it can be concluded that water hyacinth is a major bio-accumulator of $\mathrm{Mn}$, which can be used in the remediation of wastewater contaminated with this metal, especially at $\mathrm{pH} 7$.

Table 3: Bioconcentration factors of $\mathrm{Mn}$ in water hyacinth, $\frac{\mathrm{mg} / \mathrm{kg}}{\mathrm{mg} / \mathrm{L}}$.

\begin{tabular}{|c|c|c|c|c|}
\hline \multicolumn{2}{|c|}{ Initial Conditions } & $\mathrm{R}$ & $\mathrm{P}$ & $\mathrm{L}$ \\
\hline $\mathrm{C}_{0}, \mathrm{mg} / \mathrm{L}$ & $\mathrm{pH}_{0}$ & & & \\
\hline \multirow{3}{*}{10} & 3 & 168 & 227 & 178 \\
& 5 & 585 & 655 & 824 \\
& 7 & 2638 & 3911 & 3244 \\
\hline \multirow{3}{*}{50} & 3 & 534 & 433 & 154 \\
& 5 & 622 & 467 & 195 \\
& 7 & 1126 & 710 & 322 \\
\hline \multirow{3}{*}{100} & 3 & 335 & 223 & 74 \\
& 5 & 390 & 250 & 99 \\
& 7 & 799 & 323 & 101 \\
\hline
\end{tabular}

Finally, in order to assess the possible reuse of the contaminated vegetal material in nanotechnology, it was analyzed the presence of metallic aggregates within E. crassipes, and its size.

As shown in fig. 3, in samples of roots and leaves from the bioassays with $100 \mathrm{mg} \mathrm{Mn}{ }^{2+} / \mathrm{L}$ and $\mathrm{pH}_{0} 5$, it was detected the presence of Mn through EELS (fig. 3a) and it was possible to verify the existence of elementary aggregates in the samples analyzed (bright points in fig. 3b). Magnifying the image in fig.the sizes of the metal aggregates localized (fig. 3c) could be estimated: the two largest, present almost in the center of the image, measured about $20 \mathrm{~nm}$ diameter, two other particles (both located on the right side of the image, one at the top and one about half) were of size around $10 \mathrm{~nm}$, and the rest of the aggregates had a size of about $5 \mathrm{~nm}$.
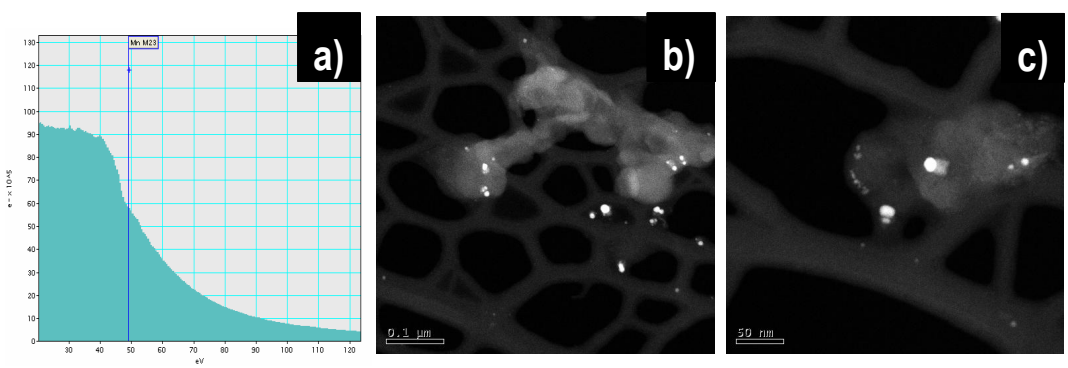

Figure 3: Root and leaf images by EELS and TEM, from bioassay at $100 \mathrm{mg} / \mathrm{L}$ and $\mathrm{pH}_{\mathrm{o}} 5$. 
Furthermore, the results of the EELS and TEM analysis of samples of petiole from the bioassay at $50 \mathrm{mg} / \mathrm{L}$ and $\mathrm{pH}_{\mathrm{o}} 7$ are shown in fig. 4. The image $4 \mathrm{a}$ showed the presence of $\mathrm{Mn}$, whereas in figs. $4 \mathrm{~b}$ and $4 \mathrm{c}$, the images obtained with TEM using clear field and dark field with a high-angle annular detector (HAADF) were shown, in both images an amorphous structure like a sponge can be seen, but in the dark field (fig. 4c) it was easier to distinguish the contrast due to the presence of metallic aggregates located at the top and at the bottom of the structure.

Thus, the formation of nanoparticles could be due to a state of located reduction state rather than to the interaction of the molecules with the metal, than which could imply the formation of microenvironments in those that the conditions around the metals were sufficient to reduce the metal and to derived in aggregates of $\mathrm{Mn}^{0}$.

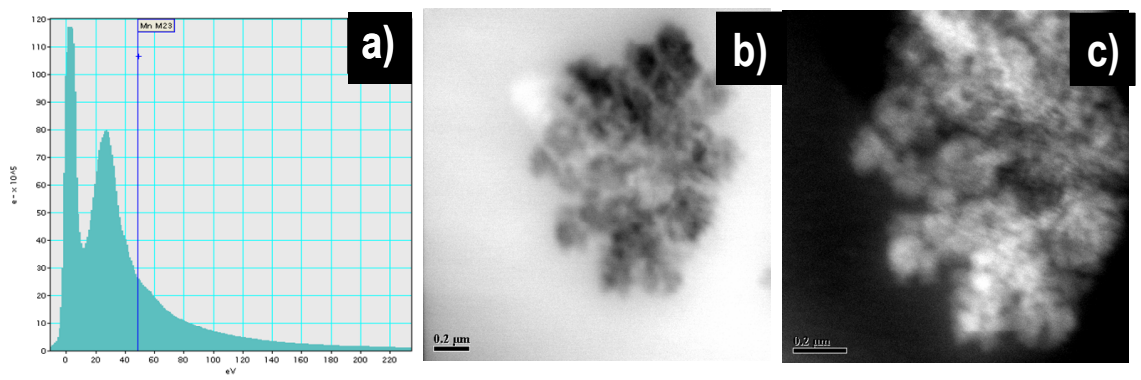

Figure 4: Petiole images by EELS and TEM, from bioassay at $50 \mathrm{mg} / \mathrm{L}$ and $\mathrm{pH}_{0} 7$.

These results confirmed the recently opened bridge between biotechnology and science of science, getting an alternative economically and scientifically viable for the disposal of the metal contaminated vegetal material, so it could be considered in an environmental friendliness sustainable exploitation of the water hyacinth, so to change its name as the worst aquatic weed worldwide to nanotechnology raw material.

\section{Conclusions}

After analyzing the results presented in this work, it could be possible to reach the following conclusions:

- The water hyacinth did not neutralize the solution that was in contact with it, the $\mathrm{pH}$ during all the tests tended to that of the carbon dioxide /water system equilibrium. 
- The EC was not a good parameter to control the metal absorption using distilled water.E. crassippeswas able to eliminate Mn effectively over a wide range of concentrations and initial $\mathrm{pH}$ values.

- The final absorption percentage of Mn showed positive dependence with $\mathrm{pH}$ for all initial concentrations studied.

- There were 2 phases of absorption: an initial phase of rapid absorption, followed by a slow one, almost linear. With the intermediate concentration $(50 \mathrm{mg} / \mathrm{L})$, it was possible to observe a cyclical behavior of the absorption kinetics.

- By increasing the initial metal concentration in water, the metal concentration in the plant $(\mathrm{mg} / \mathrm{kg})$ increased but the BCF decreased.

- $\mathrm{Mn}$ is well translocated within the water hyacinth. The metal translocation was dependent on both $\mathrm{pH}$ and concentration, increasing with both parameters.

- The presence of $\mathrm{Mn}$ in nanometric size aggregates could be revealed, suggesting that $E$. crassipes can be seen as a raw material in the field of nanotechnology.

\section{Acknowledgements}

The authors wish to thank the National Council for Science and Technology of Mexico (CONACyT) and the Autonomous University of the State of Mexico (UAEMéx) for making this research possible through funding of Projects 91184 and 2506/2007U. Also, we want to thank the IBT-UNAM and the Universidad Michoacana de San Nicolás de Hidalgo for their technical support.

\section{References}

[1] Water hyacinth control and possible uses. Technical brief or Intermediate Technology Development Group, www.Hdg.org

[2] Cordes, K.B., Mehra, A., Farago, M.E. \& Banerjee D.K., Uptake of Cd, Cu, $\mathrm{Ni}$ and $\mathrm{Zn}$ by the water hyacinth, Eichhnornia crassipes (Mart.) solms from pulverized fuel ash (PFA) leachates and slurries. Environmental Geochemistry and Health, 22, pp. 297-316, 2000.

[3] Mehra, A., Farago, M.E. \& Banerjeee, D.K., A study of Eichhornia crassipes growing in the overbank and floodplain soils of the River Yamuna in Delhi, India. Environmental Monitoring and Assessment, 60, pp. 25-45, 2000.

[4] Fritioff, A., Kautsky, L. \& Greger, M., Influence of temperature and salinity on heavy metal uptake by submerged plants. Environmental Pollution, 133, pp. 265-274, 2005.

[5] Mirkin, C.A., Letsinger, R.L., Mucic, R.C. \& Storhoff, J.J., A DNA-based method for rationally assembling nanoparticles into macroscopic materials. Nature, 382, 607-606, 1996. 
[6] Mirkin, C.A. \& Taton, T.A., Materials chemistry: semiconductors meet biology. Nature, 405, 626-627, 2000

[7] Boyce Thompson Institute, www.geocities.com/pbarrosvanc/tema12.html.

[8] Rosas, I., Báez, A., Belmont, R. \& Gómez, S., Eichhornia crassipes como un indicador de la presencia de cadmio. Revista geofisica, Instituto Panamericano de Geografía e Historia, 12, pp. 43-54, 1980.

[9] Kay, S.H., Haller W.T. \& Garrard L.A., Effects of heavy metals on water hyacinths (Eichhornia crassipes (Mart.) Solms). Aquatic Toxicology, 5, pp. 117-128, 1984.

[10] Mazen, A.M.A. \& El Maghraby, O.M.O., Accumulation of cadmiun, lead y strontium and a role of calcium oxalate in water hyacinth tolerance. Biologia Plantarum, 40(3), pp. 411-417, 1998.

[11] Soltan, M.E. \& Rashed, M.N., Laboratory study on the survival of water hyacinth under several conditions of heavy metal concentrations. Advances in Environmental Research, 7, pp. 321-334, 2003.

[12] Akcin, G., Güldede, N. \& Saltabas, O., Zinc removal in strongly basic solutions by water hyacinth. Environmental Science and Health, A28(8), pp. 1727-1735, 1993.

[13] Vesk, P.A., Nockolds, C.E. \& Allaway, W.G., Metal localization in water hyacinths roots from an urban wetland. Plant, Cell and Environment 22(2), pp. 149-158, 1999.

[14] O'Keeffe, D.H., Hardy, J.K. \& Rao R.A., Cadmium uptake by the water hyacinth: effects of solution factors. Environmental Pollution, 34A, pp. 133-147, 1984.

[15] Hardy, J.K. \& Raber N.B., Zinc uptake by the water hyacinth: effects of solution factor. Chemosphere, 14(9), pp. 1155-1166, 1985.

[16] Wolverton, B.C. \& McDonald, R.C., Bioaccumulation and detection of trace levels of cadmium in aquatic systems by Eichhornia crassipes. Environmental Health Perspectives, 27, pp. 161-164, 1978.

[17] Wang, W. \& Lewis, M.A., (eds). Metal accumulation by aquatic macrophytes, Plants for Environmental Studies: Lewis, Boca Raton, 1997. 